\title{
Rheological, Mineralogical and Strength Variability of Concrete Due to Construction Water Impurities
}

\author{
Paul O. Awoyera ${ }^{1, a^{*}}$, Oyinkansola Awobayikun ${ }^{1, b}$, Ravindran Gobinath ${ }^{2, c}$, \\ Amelec Viloria ${ }^{3,4, \mathrm{~d}, \mathrm{e}}$, Emmanuel I. Ugwu ${ }^{5, f}$ \\ ${ }^{1}$ Department of Civil Engineering, Covenant University, Ota, Nigeria \\ ${ }^{2}$ Centre for Construction Methods and Materials, S R Engineering College, Warangal, India \\ ${ }^{3}$ Univeridad de la Costa, Barranquilla, Colombia \\ ${ }^{4}$ Universidad Peruana de Ciencias Aplicadas, Lima, Peru \\ ${ }^{5}$ Department of Civil Engineering, Michael Okpara University of Agriculture, Umuahia, Nigeria \\ apaul.awoyera@covenantuniversity.edu.ng, boyinkansolaawobayikun@gmail.com, \\ 'gobinathdpi@gmail.com, daviloria7@cuc.edu.co, eamelec.viloria@upc.pe \\ ‘emmanuelugwu@mouau.edu.ng
}

Keywords: Concrete Mixing; Hydration; Mineralogy, Morphology; Rheology; Strength; Water

\begin{abstract}
Various national and international standards recommend potable water for mixing concrete; however, the availability of potable water is virtually a daunting task in some developing communities. Concrete workers in such environments tend to utilize any available water for mixing concrete, and this may be detrimental to the quality of the concrete being produced. This study investigates the rheological, mineralogical and strength variability of concrete due to construction water impurities. Water samples were collected from four different construction sites within Southwestern region of Nigeria for production of concrete. The physical and chemical properties of the waters were determined so as to measure their rate of contamination, prior to their use for mixing concrete. The rheological properties of the fresh concrete, compressive strength, split tensile strength, and microscale features of hardened concrete, that were produced with each water sample were determined. From the results, the rheological features of concrete were found not to be affected by water impurities, however, the mechanical test results revealed about $10 \%$ reduction in strength between concrete made with water having least and higher concentration of impurities. Also, it was evident from the microscale tests that the water impurities do alter the hydration rate of concrete, which results in strength reduction. The study suggests pretreatment of concrete mixing water before use in order to avoid its damaging effect on concrete life.
\end{abstract}

\section{Introduction}

Concrete mixing water is so significant in projects, in that it influences workability, hydration process, and overall strength development in concrete. However, when impurities are present in construction water, the aforementioned properties may be consequently hindered. One of the most important factors that determine the life span of any structure is the strength of the concrete used for construction; however, the strength of any concrete is determined by the combined efficiency and adequacy of each of its constituent materials. This research is focused on the quality of water used in mixing concrete and its effects on the workability and strength of the concrete. Water serves a vital role in concrete mixture, for instance, it is used for wetting the aggregate surfaces in order to enhance adhesion between the cement and the aggregates, as adhesion will surely be poor on a dry surface, and also used when moisturizing the cementing materials temporarily to harden properly during the curing period.

The quality of water used during the concrete mixing process could maintain or alter the expected level of strength of concrete. Certain chemical compounds, when present in water may seriously alter the strength, durability and setting time of concrete. Some of these compounds include nitrate [1], limestone and anhydrite [2, 3], sulfate and sulfate-chloride [4].The rheological properties of 

concrete could also be affected because these chemical compounds or impurities in the water might affect the ease of placement and consolidation, thereby causing entrapment of air voids and aggregate segregation. Although, if the contamination level of the water is within acceptable limits, such water is not expected to affect concrete properties [5]. The impurities present in water are mostly in relation to the source of the water, which could be well water, tap water, borehole water and wastewater. Potassium and Sodium have certain carbonates and bicarbonates and these components may alter the setting time of fresh concrete. It was also proven that the use of sludge water as the mixing water for concrete production will reduce the concrete strength and slump significantly[6]. Also, water having high amount of chloride is not appreciated for concrete mixing to prevent corrosion of reinforcement bars or prestressing strands, by chloride ions [7].

Water which possesses acidic properties tends to be more combative in action and it can be said that the higher the level of acidity of water used for mixing concrete, the higher the level of attack on concrete. Generally, acidic solutions when used in mixing concrete, although does not bring about expansion, dissolves areas of the cement, removing the cementing materials, thus weakening the material making it soft and semi liquid in texture [8]. With this, the long-term effect of concrete prepared using water containing some acidic properties on a structure can be predicted and avoided. Research has also shown that water with a $\mathrm{pH}$ value below 12.5 may behave aggressively with the concrete [9], because the decrease in the fluid alkalinity can eventually render the cementing material less effective. The rate at which the chemical reaction occurs also depends on the concrete permeability. For instance, a concrete with low permeability in contact with fluid of $\mathrm{pH}$ above 6 will cause a slow attack. This attack can result in cracking, decrease in its ability to withstand load, permeability and failure [9]. Addressing the issue of acidity and alkalinity, any water that has a $\mathrm{pH}$ value that falls within the range of 6.0 and 8.0 is suitable for use in concrete mixing [10]. Water free from impurities or that, which contains very minimal impurities; distilled or potable water, is the most suitable for concreting because there are little or no harmful properties present in the water.

So far in literatures, some studies have investigated the impact of contaminated water or wastewater on concrete properties. However, with a series of building deterioration and failure experienced in some parts of Nigeria over the years, it is necessary to perform this study. When buildings fail, investigators question the quality of materials, design and supervision as a possible cause of failure, without paying due attention to concrete mixing water. Since mixing water triggers cement hydration and aids strength development in concrete, then this kind of material also needs adequate check. Therefore, the rheological, mineralogical and strength variability of concrete due to construction water impurities is investigated in this study.

\section{Materials and Method}

\subsection{Materials}

A cement of grade $42.5 \mathrm{~N}$ was used in the concrete preparation. River sand of sizes not bigger than $4.75 \mathrm{~mm}$, obtained from River Ogun in Ogun State, Nigeria, was used as the fine aggregate. Crushed granite obtained from a quarry site in Igbo-ora, Ogun State, Nigeria, was used for this research, with sizes $\leq 19 \mathrm{~mm}$. The physical properties of the aggregates are shown in Table 1 . The procedures for determination of the material properties followed those of the following studies [11-14]. The water samples were obtained from part of concrete mixing water from three construction sites within Lagos and Ogun state, Nigeria. But a fourth sample, which was used for making the reference mix, was taken from a borehole. From interaction with construction workers in the region, it was realized that the water was usually sourced from nearby rivers to the sites. Thus, these locations were selected for the study owing to the numerous construction activities that are continually carried out in the region. More importantly, this research considers the fact that large numbers of building failures have occurred in the region than any other part of Nigeria over the last few decades. Thus, there is need to intensify forensic investigation on construction sites in this region. For the water tests, one sample was taken per site, but double tests were performed on each sample, and the average of the data was calculated. 
Table 1. Materials' characteristic features

\begin{tabular}{lll}
\hline Properties & River sand & Crushed Granite \\
\hline Specific gravity & 2.61 & 2.87 \\
Water absorption (\%) & 2.24 & 0.23 \\
Fineness modulus (\%) & 2.24 & 6.95 \\
\hline
\end{tabular}

\subsection{Methods}

\subsubsection{Water tests}

To properly examine the effects of various impurities and chemical substances on concrete, each water sample from each site was tested to know the unseen constituents of the water. For this experiment, physical tests and chemical tests were carried out on the water samples.

The physical parameters tested for in the water samples are as follows: Temperature, electrical conductivity, $\mathrm{pH}$, total dissolved solids, total suspended solids, and salinity. These physical parameters were measured using a multi-parameter pocket pro tester, which was duly calibrated prior to use in order to ensure accuracy of measurements. Figure 1 shows the multi-parameter pocket pro tester being used to determine certain parameters in a water sample.

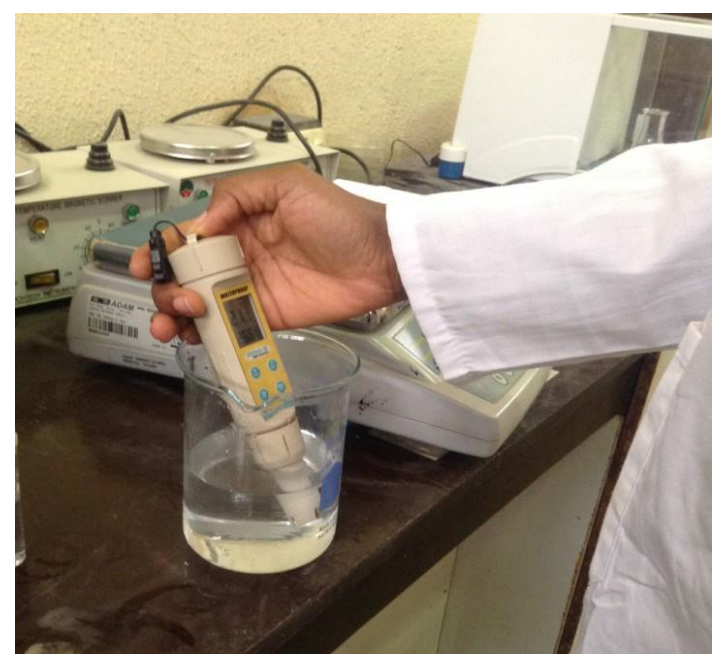

Figure 1. Physical testing of water samples.

The physical parameter that was measured without the use of the multi-parameter pocket pro tester was the total suspended solids. This was measured by pouring the water samples through a whatman filter paper. After the water was completely drained from the filter paper, the filter paper was oven dried at a temperature of $104^{\circ} \mathrm{C}$ and then weighed. The difference in the weight of the water before passing through the filter paper and after passing through the filter paper is the total suspended solids in the water sample. Figure 2 shows the test for total suspended solids in water samples, using a filter paper. 

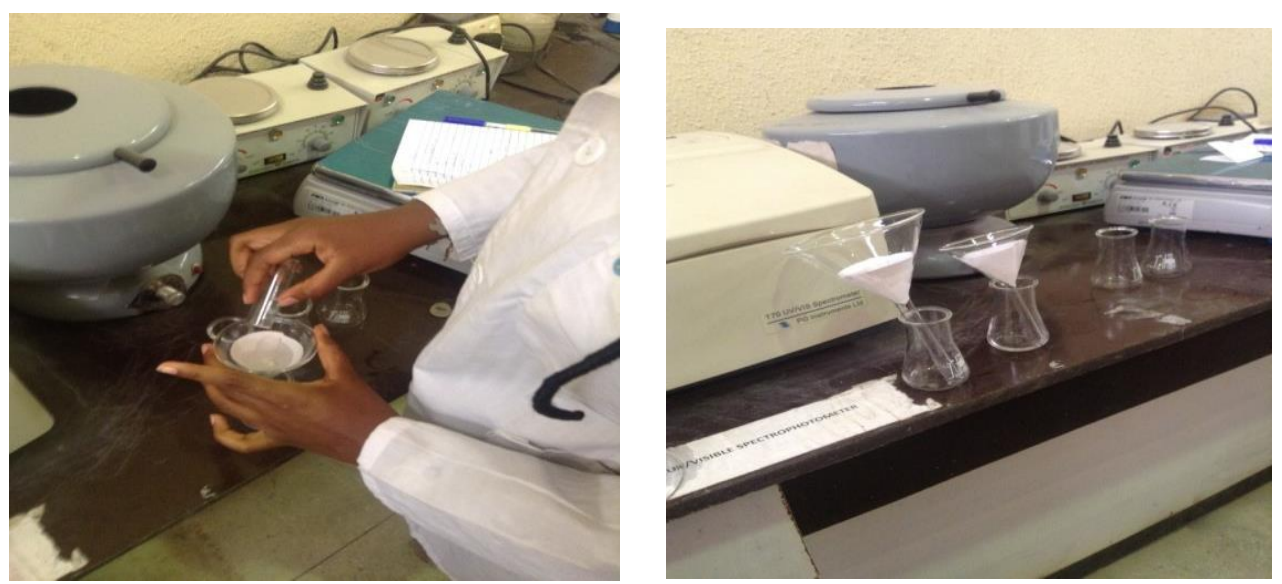

Figure 2. Test for the total suspended solids in the water samples.

The chemical tests on the water samples are the most essential tests for this experiment, because they are unseen substances and could be detrimental to concrete. If these chemical substances are not properly managed, the concrete could undergo disintegration due to sulfate attack and acid attacks, as a result of these chemicals. The parameters examined from the water samples are: calcium $(\mathrm{Ca})$, chlorine $(\mathrm{Cl})$, fluoride $(\mathrm{FL})$, iron $(\mathrm{Fe})$, lead $(\mathrm{Pb})$, potassium $(\mathrm{K})$, sulphate $\left(\mathrm{SO}_{4}\right)$, and sodium $(\mathrm{Na})$. The parameters were determined using: Palin test photometer, reagents, and test tubes. Figure 3 shows the chemical testing on the water samples using the Palin test photometer.

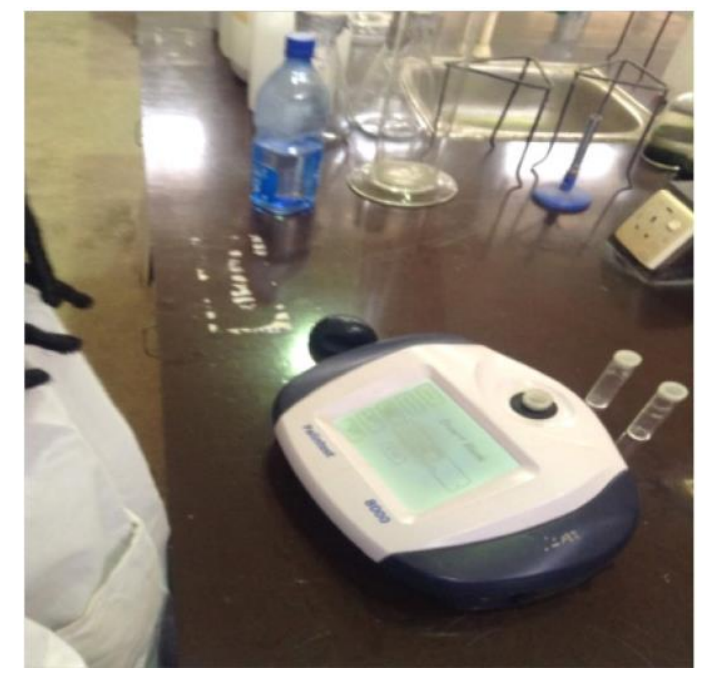

Figure 3. Chemical tests on water samples

The chemical substances were tested for using specific reagents, depending on the intended substance to be detected. These reagents are in tablet form and are crushed in a maximum of $10 \mathrm{ml}$ of the water samples. The test tube with the water and the crushed tablet is placed in the Palin test photometer. The photometer immediately shows the concentration of the chemical substance in $\mathrm{mg} / \mathrm{l}$.

\subsubsection{Concrete mix design and preparation, and testing}

For this experiment, batching by weight method was adopted and an established concrete mix ratio of 1:2:4 was adopted for mixing concrete with each water sample. This was used to cast concrete cubes of $150 \mathrm{~mm} \times 150 \mathrm{~mm} \times 150 \mathrm{~mm}$ and cylinders of $100 \mathrm{~mm}$ diameter by $200 \mathrm{~mm}$ height, with a water cement ratio of 0.55 . The densities of the concrete materials used are shown in Table 2 .

Table 2. Densities of materials used

\begin{tabular}{lllll}
\hline & Cement $\left(\mathrm{kg} / \mathrm{m}^{3}\right)$ & Sand $\left(\mathrm{kg} / \mathrm{m}^{3}\right)$ & Granite $\left(\mathrm{kg} / \mathrm{m}^{3}\right)$ & Water $\left(\mathrm{kg} / \mathrm{m}^{3}\right)$ \\
\hline Typical mix & 427.14 & 854.27 & 1708.54 & 234.92 \\
\hline
\end{tabular}


For each water sample, 9 cubes and 6 cylinders were produced. The cubes and cylinders are left to set for 24 hours after placing, and then curing starts after 24 hours. Slump test was done performed to examine the workability of the concrete. The curing process adopted for this experiment is curing by immersion, until a maximum period of 28 days. During this period, compressive and split tensile strength tests were conducted at intervals, to determine the concrete strength at its early days and at maturity. This was done after 7, 21 and finally, after 28 days.

Triplicate concrete cubes and two concrete cylinders, originating from each water sample, were tested during the curing period, to obtain compressive strength and split tensile strengths, respectively. The strength test was performed using a compressive strength machine, and it was done at 7,21 and 28 curing days. This helps to examine the early strength of the concrete and the strength development in the concrete towards the later days of curing. The compressive strength of the cubes was calculated thus:

Compressive Strength $\left(\mathrm{N} / \mathrm{mm}^{2}\right)=\frac{\text { Crushing Load }(\mathrm{N})}{\text { Area of Cubes }\left(\mathrm{mm}^{2}\right)}$

Split tensile test was carried out on concrete cylinders in doubles using the compressive strength test equipment. It was carried out conventionally, placing planks above and below the cylinders before subjecting it to loading.

Split Tensile Strength $\left(\mathrm{N} / \mathrm{mm}^{2}\right)=\frac{2 P}{\pi \times D \times H}$

$\mathrm{P}=$ Failure Load $[\mathrm{N}]$

$\mathrm{D}=$ Cylinder Diameter $[\mathrm{mm}]$

$\mathrm{H}=$ Cylinder Height $[\mathrm{mm}]$

The scanning electron microscope was used on hardened concrete to examine its morphology. As such, the tests guide on how the water samples have influenced hydration in the concretes.

\section{Results and Discussion}

\subsection{Physical tests on waters}

The first tests carried out on the water samples are the physical tests, which include temperature, $\mathrm{pH}$, conductivity, salinity, total dissolved solids and total suspended solids. Figure 4 shows the levels of suspended solids present in the water samples in $\mathrm{mg} / \mathrm{l}$. High number of suspended solids present in water, eliminates the suitability of that water to be consumed.

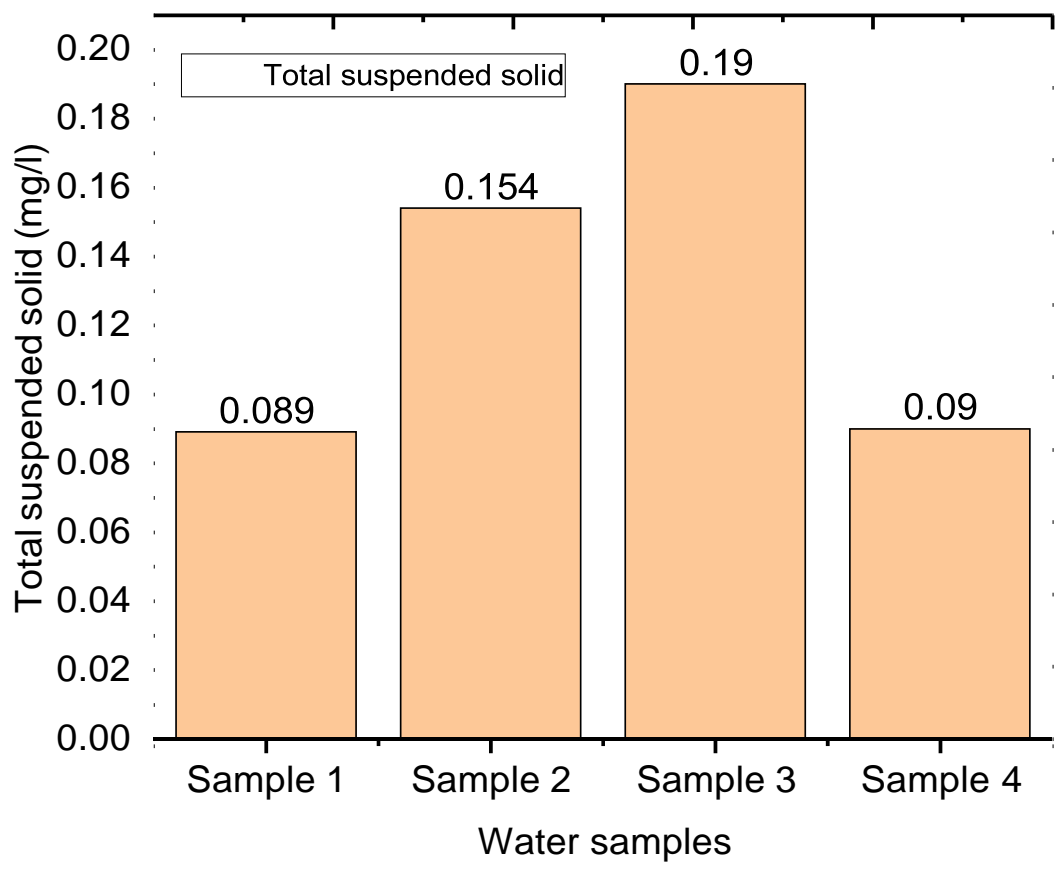

Figure 4. Total suspended solids of water samples. 
Generally, water containing suspended solids should be left to settle before it is used in mixing concrete. Figure 4 shows generally low levels of suspended solids in all the water samples. However, sample 3 has the highest amount of suspended solids and it was observed that there was a small amount of visible particles in water samples 2 and 3. The acceptable limit of suspended solids for concrete mixing water is $2000 \mathrm{mg} / \mathrm{l}$ [15]. The amount of suspended solids in these water samples will have little or no effect on the concrete mixed with them.

Figure 5 shows the $\mathrm{pH}$ values of the tested water samples. It is clear that water sample 3 , has a highest amount of suspended solids. It is observed that samples 2 and 3 possess visible suspended solids, which make these samples unsuitable for consumption. Being unsuitable for consumption, it may or may not have adverse effects on the strength gain of the concrete. The other physical properties of the water samples were detected in their respective quantities using a multimeter apparatus. The multimeter was partly submerged in the water sample and as the mode was changed, the parameter and the level to which it was present in the water sample was shown and recorded.

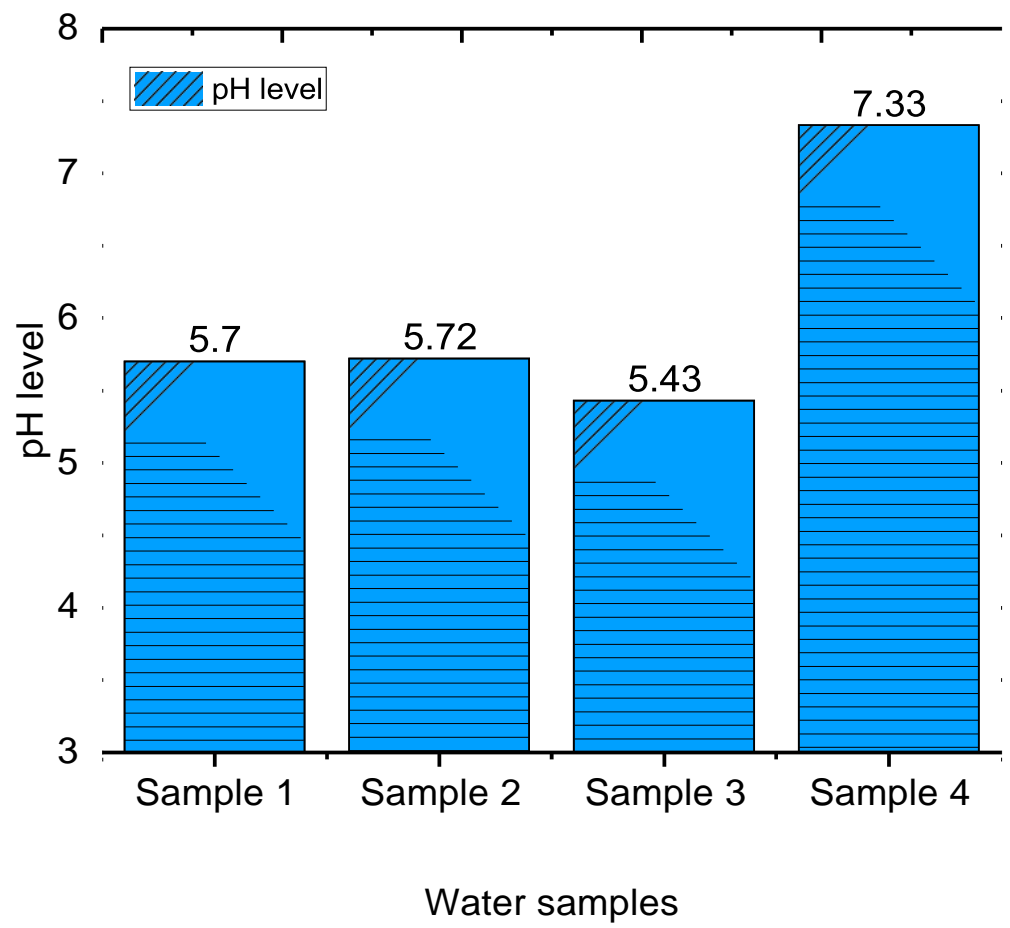

Figure 5. pH levels of water samples.

The $\mathrm{pH}$ is a measure of the corrosivity of water. The World Health Organization (WHO) stipulated that any water with a $\mathrm{pH}$ value between 6.5 and 8 is suitable for consumption [16]. However, not every water sample unsuitable for consumption is unfit for use in mixing concrete. Generally, $\mathrm{pH}$ values lower than 7 should not create any form of concern unless the $\mathrm{pH}$ value is less than 5 [17]. This will result in an attack on the durability and strength of concrete as the concrete ages.

Water for mixing concrete should be alkaline, therefore having a $\mathrm{pH}$ value that falls within the range $7.2-7.6$ [15]. From Figure 5, it is evident that sample 3 is the most acidic, and sample 4 is the most alkaline of all the samples.

Figures 6, 7 and 8 show the salinity level of water samples used in this research. The salinity level of the water samples refers to the total quantity of dissolved salts in the water samples. The conductivity of a water sample gives a measure of the rate at which the water will conduct electricity. It is a measure of the dissolved metals present in a water sample. Determination of the salinity and conductivity of a water sample is an indirect method of determining the total dissolved solids in that water sample as these dissolved solids contribute to the salinity and conductivity of the water sample. 


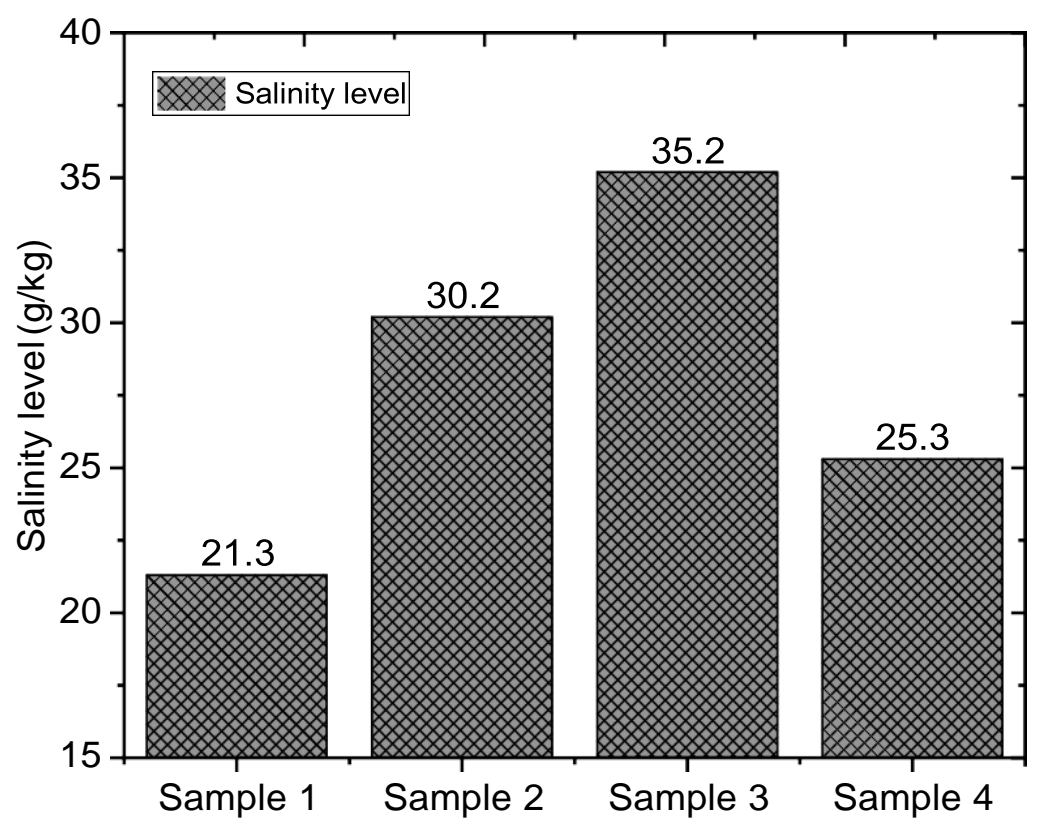

Water samples

Figure 6. Salinity levels of water samples.

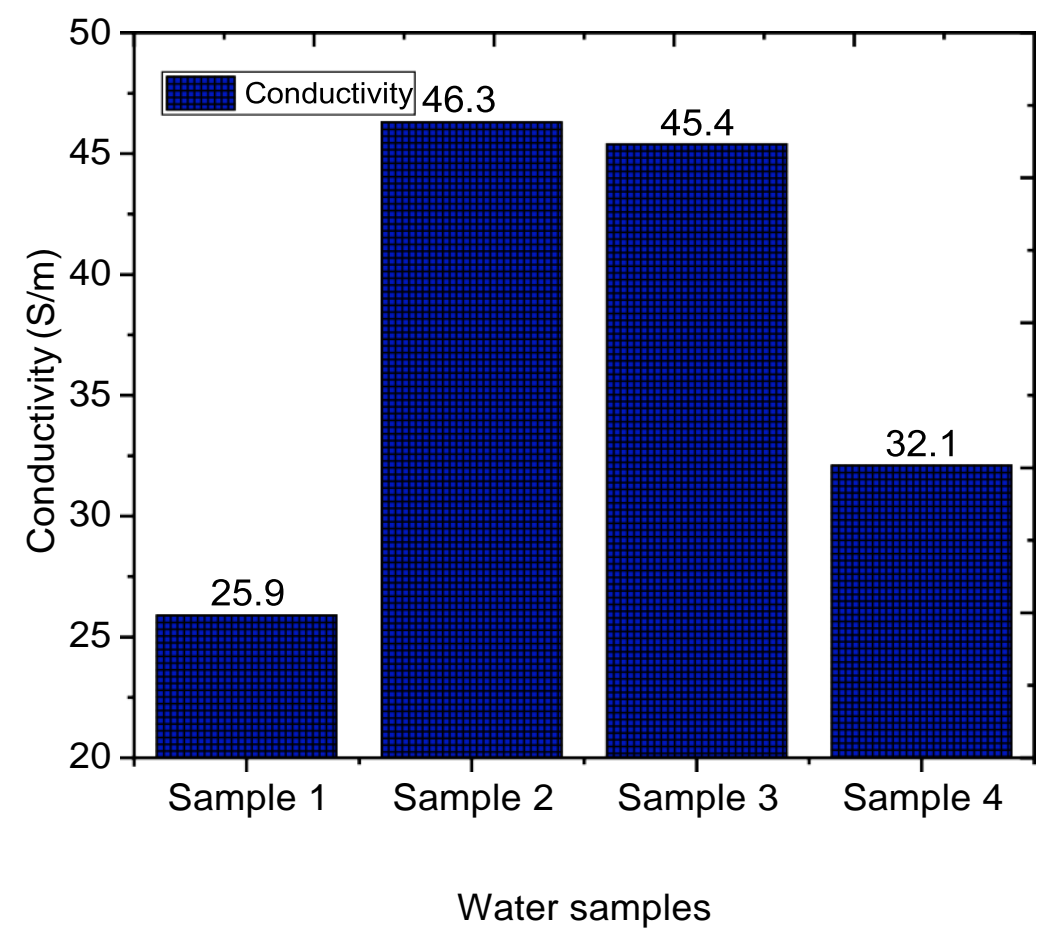

Figure 7. Conductivity levels of water samples 


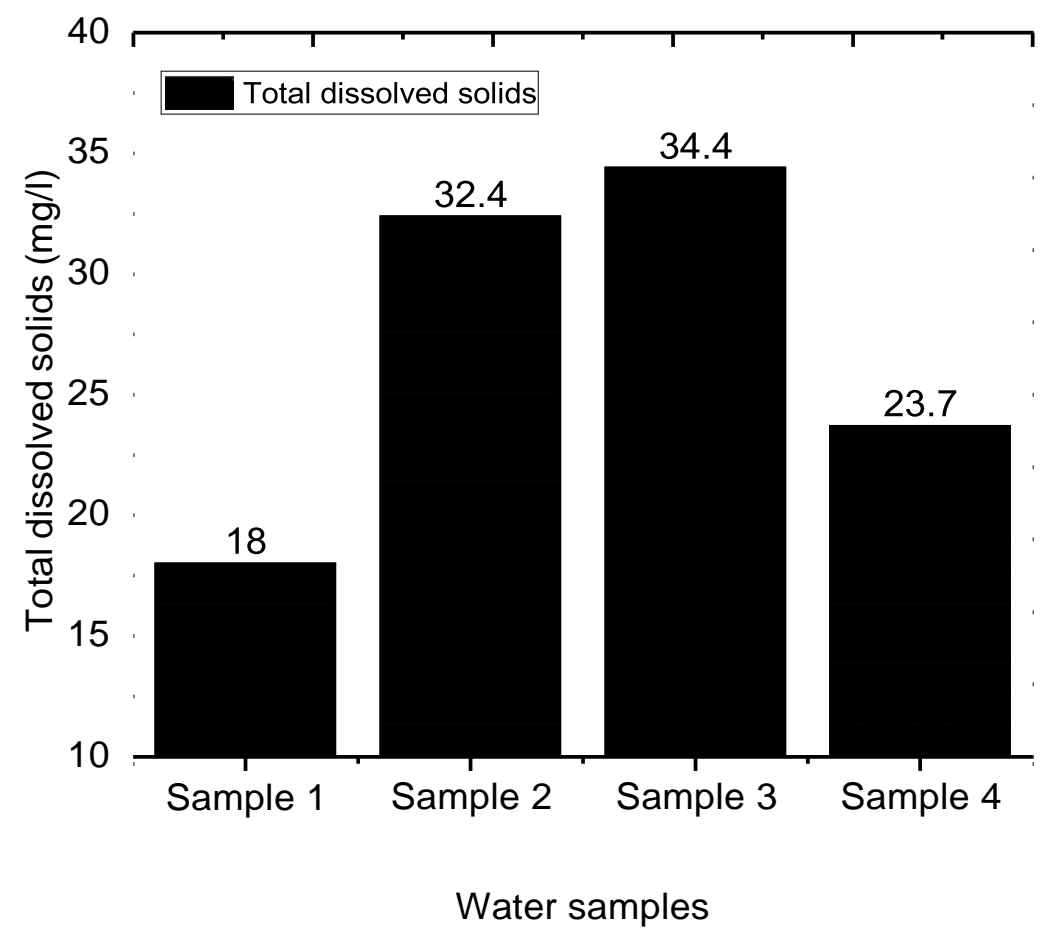

Figure 8. Plot of total dissolved solids of water samples

Salinity in water may exist in different forms and could have varying effects. The effects of salinity on concrete may be either physical or chemical. There have been varying results on the effects of salinity on concrete and this could be attributed to a change in the mode of manufacturing of cement, the chemistry involved, the type of salinity, amongst others. Earlier studies have shown that increasing salinity reduces the strength of concrete, while recent studies have indicated little or no effect on the compressive strength of concrete [18].

From Figure 6, sample 3 has the highest amount of dissolved salts present, and sample 1 which is the control water sample, has the lowest salinity. The dissolved salts in water are referred to as electrolytes, which produce solutions that conduct electricity. Based on these results, the levels of conductivity of these samples may be partly attributed to the active nature of the dissolved salts present in the water samples, as the conductivity levels are generally higher than the salinity levels. Figure 7 shows that samples 2 and 3 have the highest conductivity levels, as compared to the other samples, but are of similar levels. This indicates the presence of more dissolved metals in these samples. Figure 8 shows the total dissolved solids present in the water samples which is a combination of the dissolved metals, salts, organic materials and other inorganic materials present in the water samples. Any water that contains less than 2000 ppm of total dissolved solids can be used in mixing concrete [5]. All water samples used in this research fall within the permissible range of allowable dissolved solids in concrete mixing water. However, it shows clearly that sample 3 has the highest amount of dissolved solids present.

\subsection{Chemical tests on waters}

The chemical tests on the water samples were carried out using a Palintest photometer. For each chemical substance, tablets were provided. These tablets were crushed into $10 \mathrm{ml}$ of the water samples in a test tube and placed into the photometer. The level to which the chemical substances were present in the water samples was indicated on the photometer after that. Table 3 shows the concentrations of certain chemical constituents present in the water samples. 
Table 3. Chemical constituents of water samples.

\begin{tabular}{lllll}
\hline $\begin{array}{l}\text { Chemical } \\
\text { Constituents } \\
(\mathrm{mg} / \mathrm{l})\end{array}$ & Sample 1 & Sample 2 & Sample 3 & Sample 4 \\
\hline Calcium, $\mathrm{Ca}$ & 97.00 & 61.00 & 80.00 & 73.00 \\
Chloride, $\mathrm{Cl}^{-}$ & 1.00 & 2.40 & 1.70 & 3.10 \\
Fluoride, $\mathrm{Fl}^{-}$ & 0.50 & 0.90 & 1.30 & 1.10 \\
Iron, Fe & 0.01 & 0.01 & 0.07 & 0.00 \\
Lead, $\mathrm{Pb}$ & 0.00 & 0.00 & 0.00 & 0.01 \\
Potassium, $\mathrm{K}$ & 0.00 & 1.80 & 2.50 & 1.60 \\
Sulfate, $\mathrm{so}{ }_{4}^{2}$ & 0.00 & 9.00 & 7.00 & 7.00 \\
Sodium, $\mathrm{Na}$ & 10.00 & 20.00 & 50.00 & 35.00 \\
\hline
\end{tabular}

Water with high amounts of Fluoride and Chloride ions will lead to corrosion of reinforcement bars used in concrete. Fluoride is a member of the family of halides amongst chemical elements. Halides include iodine, chlorine, bromine, fluorine and also astatine. When fluorine is present in concrete, it forms calcium fluoride that is insoluble, and this forms fluoride ions that cause corrosion in reinforcement bars [19]. Chloride has acceptable limit of $2000 \mathrm{mg} / \mathrm{l}$ for water used for plain concrete and $500 \mathrm{mg} / \mathrm{l}$ for water used for reinforced concrete [20]. Fluoride has an acceptable limit of $1 \mathrm{mg} / \mathrm{l}$ [21]. From Table 3, it is evident that all the water samples have chloride contents that fall within the acceptable limits. It also shows that samples 3 and 4 have fluoride contents a little higher that the recommended value for use in mixing concrete. The effects of these chemical substances on reinforcement bars cannot be properly assessed through this research, because plain concrete was used throughout. High chlorine contents could also lead to efflorescence on concrete, but that was not observed in the study.

Sodium mostly exists as a dissolved salt in water, i.e. sodium chloride $(\mathrm{NaCl})$, and excessive amounts of these dissolved salts in concrete is detrimental to the strength gain of concrete. The permissible limit for sodium in concrete mixing water is $1500 \mathrm{mg} / \mathrm{l}$ [8]. Table 3 also has shown that the water samples have sodium contents that fall within the permissible limits, but with sample 3 having the highest level of sodium present. High amounts of sulphates in concrete could lead to sulphate attack and significantly reduce concrete durability. Water suitable for mixing concrete must not have sulphate content higher than $400 \mathrm{mg} / 1$ [18]. From Table 2, the water samples do not exceed this acceptable limit. Sample 1, which is the control sample of this experiment does not contain sulphate and sample 2 has a sulphate concentration of $9 \mathrm{mg} / \mathrm{l}$, which is the highest value. Chemical elements like calcium and Potassium do not act on their own. They combine with chlorine to form chlorides and as earlier stated, these chlorides are the primary cause of reinforcement corrosion.

\subsection{Slump test}

The slump test was carried out to determine the level of workability of concrete. This directly affects the strength of concrete. Each mix design was done with the same water cement ratio in order to achieve accurate results. Figure 9 shows the slump values of the concretes. 


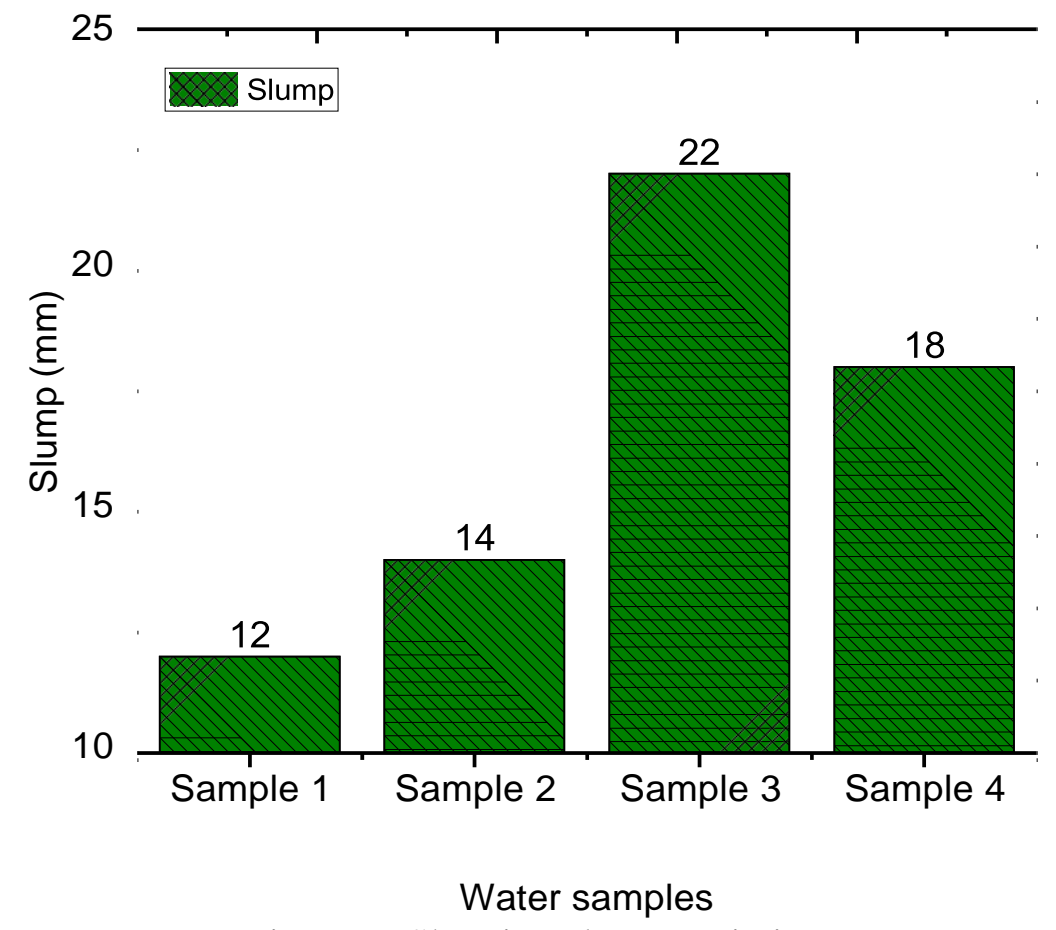

Figure 9. Showing slump variation

From Figure 9, sample 3 has the highest slump value of $22 \mathrm{~mm}$. All the concrete mixes produced true slumps and were all done under the same conditions; therefore, this may be attributed to the fact that impurities in concrete mixing water has no significant effect on workability of concrete.

\subsection{Strength Properties}

Figure 10 shows the compressive strength comparison of concrete. The concrete samples have been denoted according to the water sample numbers. It can be seen that after 7 days, the control sample (sample 1) with the least amount of impurities has the highest strength in comparison to the other concrete samples. The other samples have strengths slightly lower than that of the control sample, but with sample 3 having the lowest compressive strength.

The 21 days strength also follow the same trend as the 7 days compressive strength, with sample 1 having the highest compressive strength with a strength gain of $3.78 \mathrm{~N} / \mathrm{mm}^{2}$ and sample 3 having the least compressive strength with a strength gain of $3.04 \mathrm{~N} / \mathrm{mm}^{2}$. Sample 1 has the highest 28 days compressive strength of $26.15 \mathrm{~N} / \mathrm{mm}^{2}$ and a strength gain between 21 and 28 days of $2.15 \mathrm{~N} / \mathrm{mm}^{2}$. Sample 3 has the lowest compressive strength of $22.15 \mathrm{~N} / \mathrm{mm}^{2}$ and a strength gain of $1.19 \mathrm{~N} / / \mathrm{mm}^{2}$. 


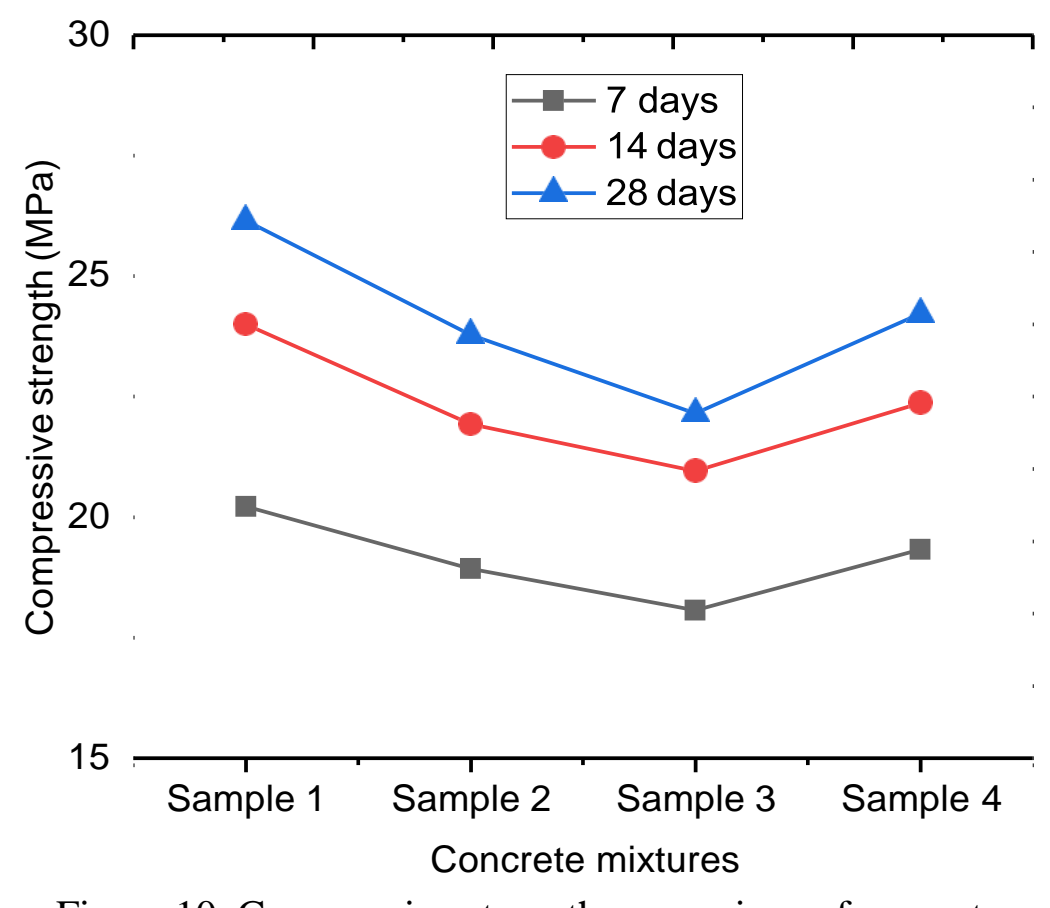

Figure 10. Compressive strength comparison of concrete

From Figure 10, it is evident that the concrete cubes all gained strength as the curing days increased, but the strength was gained at different rates. It also shows clearly that the concrete cubes cast with water sample 3 maintained the lowest compressive strength throughout the curing period. The cubes cast using the water sample 3 have the lowest rate of strength gain. This may be attributed to the collective effect of all the impurities present in the water sample, because, as seen from Figures 6, 7 and 8 , water sample 3 has the highest level of salinity, dissolved and suspended solids. The chemical compositions of the water samples all fall within permissible limits, therefore any effects on the concrete will be minimal or nonexistent.

Figure 11 shows the split tensile strength comparison of the concrete samples. It can be seen that sample 1 has the highest 7 days split tensile strength in comparison to the other samples. Sample 3 has the least split tensile strength, which is a similar trend to the compressive strength of the concrete cubes. It can also be seen that there was an increase in tensile strength of the concrete samples after 21 days of curing. The split tensile strength of sample 3 is the lowest and with a strength gain of 0.4 $\mathrm{N} / \mathrm{mm}^{2}$. Sample 1 has the highest split tensile strength of $2.51 \mathrm{~N} / \mathrm{mm}^{2}$, with a strength gain of 0.22 $\mathrm{N} / \mathrm{mm}^{2}$. Sample 1 has the highest split tensile strength after 28 days and sample 3 has the lowest tensile strength. Sample 1 increased by $0.32 \mathrm{~N} / \mathrm{mm}^{2}$ and sample 3 increased by $0.32 \mathrm{~N} / \mathrm{mm}^{2}$. This contradicts the research carried out by [5], which tested the effect of waste water quality on concrete and the control sample emerged with the lowest split tensile strength as compared to the concrete mixed with various quantities of waste water. 


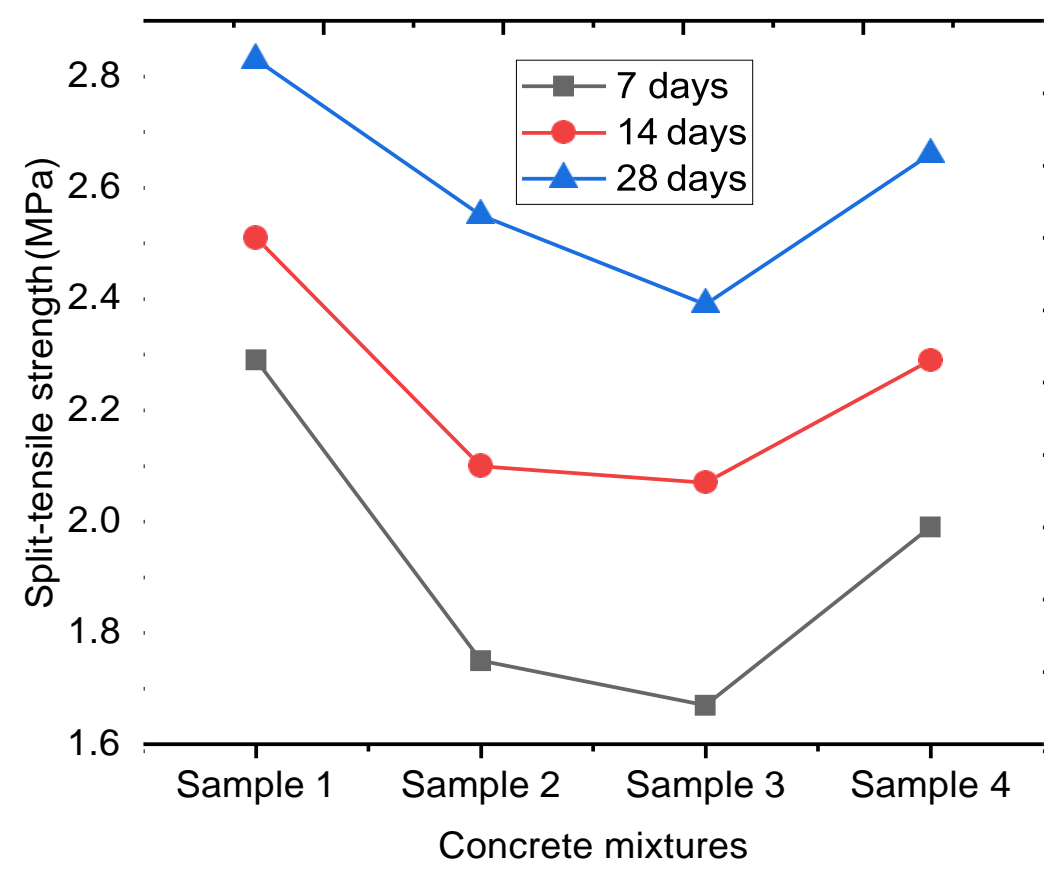

Figure 11. Split tensile strength comparison of the concrete samples.

Similar to the compressive strength of the concrete samples, the tensile strength of the concrete cubes mixed with water sample 3 remains the lowest. Although, at the early days of curing, sample 3 exhibited rapid strength gain, but this slowed down towards the later days of curing.

\subsection{SEM analysis}

The scanning electron microscope is done in order to analyze the morphology of the concrete. For this research it is used in the comparison of the changes in the microstructure of the concrete samples. Any difference observed is solely as a result of the difference in the concentration of impurities in the water samples as the concrete samples were all cast under the same conditions. The microstructure of samples 1 and 3 after 7 days are shown in Figures 12a and 12b, respectively. Sample 1 is the reference while sample 3 represents concrete produced with water having the worst level of impurities.
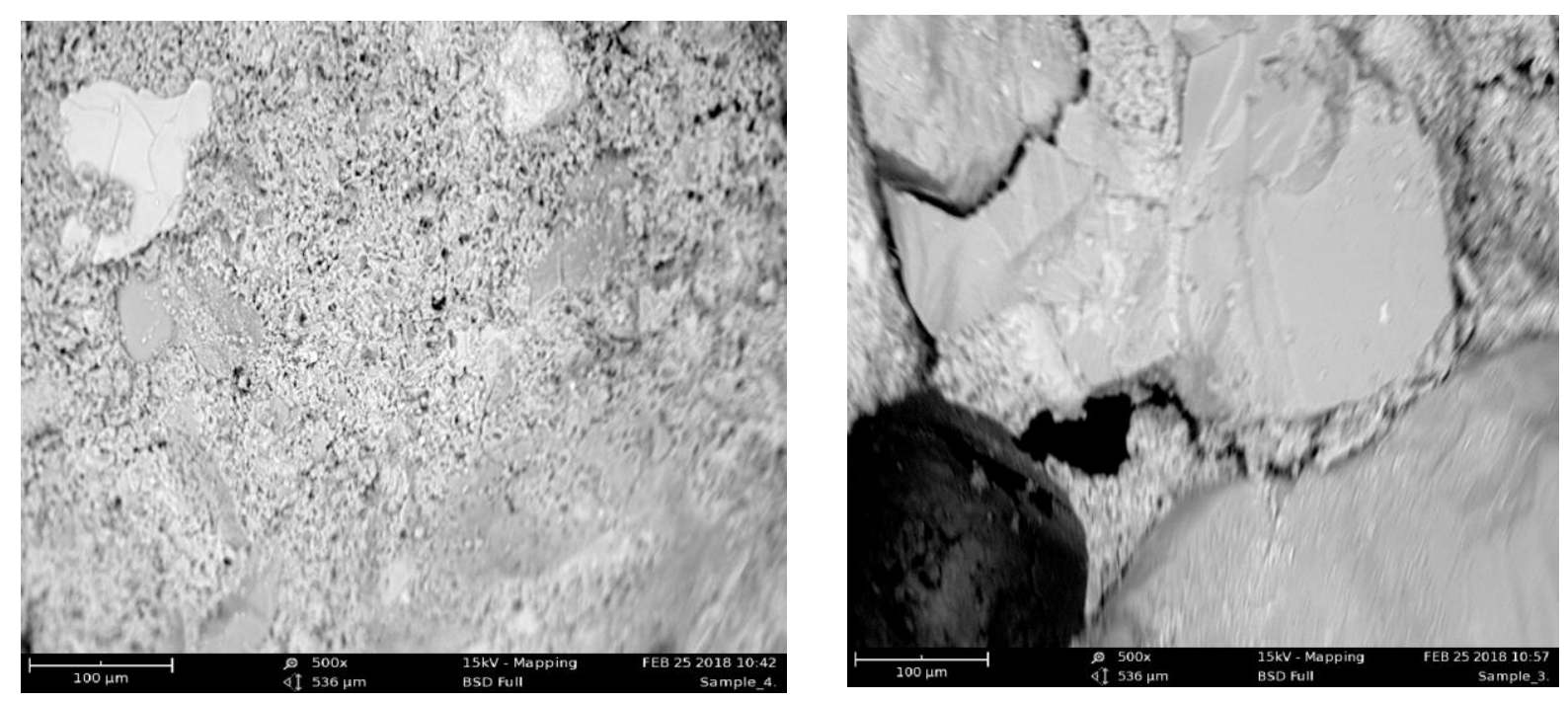

Figure 12. Micrograph of hardened concrete (a) sample 1 (b) sample 3

The micrographs show the difference in the microstructure of the hardened concrete samples after 7 days. Figure 12a shows the presence of pores and cement paste segregation in the concrete, which could be as a result of a poor bonding of constituent materials. Although, the size of these pores was 
not characterized, since it is not the focus of this study. However, large numbers or sizes of pores are generally known to have detrimental effect on the strength and performance of concrete [19]. Figure $12 \mathrm{~b}$ shows a proper bond between the concrete materials. This may be a result of rapid cement hydration or partly be attributed to the presence of minimal impurities in the water sample, amongst other factors like compaction and placement.

\section{Conclusions}

This study investigated the rheological, mineralogical and strength variability of concrete due to construction water impurities. The following conclusions can be drawn from this research:

- The negative effects of mixing water on concrete is mostly as a result of numerous impurities present. It is impossible to attribute the deficiency observed in concrete strength to one impurity in water. A typical example from this research is in Table 3, where it is indicated that the water sample 2 has the highest sulphate concentration, as compared to other water samples. This alone does not translate to water sample 2 producing concrete with the lowest strength.

- With the same water/cement ratio, fresh concrete mixed with the water sample that contains the least concentration of impurities produced the lowest slump value. This indicates a possibility for high strength in the hardened concrete.

- Water sample 3 has the highest amount of impurities harmful to concrete. In comparison to other water samples, sample 3 has the highest concentration of dissolved solids, salinity, suspended solids, sodium and fluoride.

- Although, the $\mathrm{pH}$ values of the water samples do not create a major concern, sample 3 is the most acidic water sample used in this research.

- The cube compressive strength from all the water samples increased, as the period of curing increased.

- Sample 1, which has the least impurities, produced concrete cubes with the highest compressive and split tensile strength values.

- Regardless of the small quantities of some of the impurities, the concrete mixed using the water sample 3 had the lowest compressive and split tensile strength as compared to the other mixes done with the other water samples.

\subsection{Recommendations}

Water quality in mixing concrete is often neglected and problems encountered due to poor mixing water quality in concrete structures are approached wrongly because of lack of awareness. To properly extend this research, the following suggestions may be considered:

- Any water sample with visible suspended particles should be left in a tank for some time, in order to allow the particles settle before use in mixing concrete.

- Durability tests should be carried out to determine the effect of certain concentrations of sulphate and chloride ions on concrete.

\section{References}

[1] Kumar S, Rao CVSK (1994) Effect of sulfates on the setting time of cement and strength of concrete. Cem Concr Res 24:1237-1244 . doi: https://doi.org/10.1016/0008-8846(94)90108-2

[2] Adu-Amankwah S, Zajac M, Stabler C, et al (2017) Influence of limestone on the hydration of ternary slag cements. Cem Concr Res 100:96-109 . doi: https://doi.org/10.1016/j.cemconres.2017.05.013

[3] Zajac M, Rossberg A, Saout G Le, Lothenbach B (2014) Influence of limestone and anhydrite on the hydration of Portland cements. Cem Concr Compos 46:99-108 . doi: https://doi.org/10.1016/j.cemconcomp.2013.11.007 
[4] Zhang M, Chen J, Lv Y, et al (2013) Study on the expansion of concrete under attack of sulfate and sulfate-chloride ions. Constr Build Mater 39:26-32 . doi: https://doi.org/10.1016/j.conbuildmat.2012.05.003

[5] Al-Jabri KS, AL-Saidy AH, Taha R, AL-Kemyani AJ (2011) Effect of using Wastewater on the Properties of High Strength Concrete. Procedia Eng 14:370-376 . doi: https://doi.org/10.1016/j.proeng.2011.07.046

[6] Chatveera B, Lertwattanaruk P (2009) Use of ready-mixed concrete plant sludge water in concrete containing an additive or admixture. J Environ Manage 90:1901-1908 . doi: https://doi.org/10.1016/j.jenvman.2009.01.008

[7] Rivera-Corral JO, Fajardo G, Arliguie G, et al (2017) Corrosion behavior of steel reinforcement bars embedded in concrete exposed to chlorides: Effect of surface finish.

Constr Build Mater 147:815-826 . doi: https://doi.org/10.1016/j.conbuildmat.2017.04.186

[8] Kucche KJ, Jamkar SS, Sadgir PA (2015) Quality of Water for Making Concrete : A Review of. Int J Sci Res Publ 5:1-10 . doi: 2250-3153

[9] Mehta PK, Monteiro PJM, Ebrary I (2014) Concrete: microstructure, properties, and materials. McGraw-Hill

[10] Gupta B, Gupta A (2012) Concrete Technology. Standard Publishers ltd, India

[11] Karthik S, Rao PRM, Awoyera PO (2017) Strength properties of bamboo and steel reinforced concrete containing manufactured sand and mineral admixtures. J King Saud Univ - Eng Sci. doi: 10.1016/j.jksues.2016.12.003

[12] Anandaraj S, Rooby J, Awoyera PO, Gobinath R (2019) Structural distress in glass fibrereinforced concrete under loading and exposure to aggressive environments. Constr Build Mater 197:862-870 . doi: https://doi.org/10.1016/j.conbuildmat.2018.06.090

[13] Sateshkumar S, Awoyera P, Kandasamy T, et al (2018) Impact resistance of high strength chopped basalt fibre-reinforced concrete. Rev la Construcción J Constr 17:240-249

[14] Murthi P, Awoyera P, Selvaraj P, et al (2018) Using silica mineral waste as aggregate in a green high strength concrete: workability, strength, failure mode, and morphology assessment. Aust J Civ Eng 0:1-7 . doi: 10.1080/14488353.2018.1472539

[15] Babu GR, Reddy BM, Ramana NV (2018) Quality of mixing water in cement concrete "a review." Mater Today Proc 5:1313-1320 . doi: https://doi.org/10.1016/j.matpr.2017.11.216

[16] WHO (2004) Water Sanitation and Health Programme. Managing water in the home: accelerated health gains from improved water sources

[17] AS 1379 (2007) Specification and Supply of Concrete

[18] Akinsola O, Ajibola F, Ounsanmi O (2012) Investigation of Salinity Effect on Compressive Strength of Reinforced Concrete. J Sustain Dev 5:74-82

[19] Singh DDN, Ghosh R, Singh BK (2002) Fluoride induced corrosion of steel rebars in contact with alkaline solutions, cement slurry and concrete mortars. Corros Sci 44:1713-1735 . doi: https://doi.org/10.1016/S0010-938X(01)00179-2

[20] Babu GR, Ramana NV (2018) Feasibility of wastewater as mixing water in cement. Mater Today Proc 5:1607-1614 . doi: https://doi.org/10.1016/j.matpr.2017.11.253

[21] Arif M, Hussain I, Hussain J, et al (2015) GIS-based inverse distance weighting spatial interpolation technique for fluoride distribution in south west part of Nagaur district,

Rajasthan. Cogent Environ Sci 1: . doi: 10.1080/23311843.2015.1038944

[22] Kucche K, Jamkar S, Sadgir P (2015) Quality of Water for Making Concrete:A Review of Literature. Int J Sci Res Publ 5:1-10

[23] Al-Saleh SA (2015) Analysis of total chloride content in concrete. Case Stud Constr Mater 3:78-82 . doi: https://doi.org/10.1016/j.cscm.2015.06.001

[24] Awoyera PO, Akinmusuru JO, Dawson AR, et al (2018) Microstructural characteristics, porosity and strength development in ceramic-laterized concrete. Cem Concr Compos 86: . doi: 10.1016/j.cemconcomp.2017.11.017 